\title{
O ACONSELHAMENTO LINGUAGEIRO COMO FORMA DE INTERVENÇÃO E
}

\author{
FORMAÇÃO DOCENTE
}

\author{
Rejane NONATO \\ Universidade Federal do Pará ${ }^{1}$
}

RESUMO: Essa pesquisa objetivou encontrar maneiras de melhorar a formação em serviço de professores de inglês que atuam na rede pública de ensino no interior do Estado do Pará. Para tanto, utilizei o aconselhamento linguageiro (AL) que é uma forma de suporte de língua que, por meio de conversas, visa promover o aprendizado auto direcionado (GARDNER; MILLER, 1999; RILEY, 1997; VIEIRA, 2007). Para realizá-la apoiei-me nos estudos de Mozzon-McPherson (2001), que discorre sobre o aconselhamento linguageiro, apontando as características de um bom conselheiro linguageiro; e Reinders (2007) que trata a respeito da organização das sessões de aconselhamento. A metodologia adotada enquadra-se no método de pesquisa qualitativa uma vez que se trata de uma pesquisa-ação. A sequência de procedimentos apoiou-se no projeto coordenado por Magno e Silva (2013), no qual primeiramente, analisou-se a experiência pessoal de aprendizagem de LE das aconselhadas e identificou-se uma área de preocupação pessoal; em seguida, planejou-se pró-ativamente, visando a área de preocupação pessoal; o terceiro passo foi exercer uma intervenção monitorada; por fim, como última etapa, se deu a avaliação e o replanejamento. Para a realização dessa pesquisa utilizou-se como instrumentos de coleta de dados relatórios de sessões de aconselhamento. Os resultados apresentados evidenciam que o AL pode ajudar na formação de professores em exercício favorecendo o desenvolvimento da autonomia desses profissionais, uma vez que o período de aconselhamento permitiu que as professoras aconselhadas refletissem sobre seus conhecimentos de língua, suas crenças, dificuldades e estratégias para superar essas dificuldades, levando-as a realizar ações em busca de seu aperfeiçoamento linguístico e profissional.

PALAVRAS-CHAVE: aconselhamento linguageiro; autonomia; escolas públicas.

ABSTRACT: This research aimed at finding ways to improve the in-service training of English teachers from countryside public schools of Pará State. In order to do so, I used the language advising (LA) which is a form of language support that through conversations, aims at promoting self-directed learning (GARDNER; MILLER, 1999; RILEY, 1997; VIEIRA, 2007). I based myself on Mozzon-McPherson (2001), which is about language advising, pointing out the characteristics of a good language adviser, and Reinders (2007) that deals with the organization of an advising session. The research methodology belongs to the qualitative research method since it is an action research. The sequence of procedures was nested in the project coordinated by Magno e Silva (2013), in which firstly, the advisee's personal experience of learning the FL was analyzed and an area of personal preoccupation was identified. Then it was planned proactively targeting the area of personal preoccupation, the third step was to exert a monitored intervention, and finally, as a last step, it was done the evaluation and the replanning. To carry out this research it was used as instruments of data collection reports of advising sessions. The results indicated that the LA can help in the formation of teachers in practice favoring the development of autonomy of these professionals, once the advising period allowed teachers reflect on their language knowledge, their beliefs, difficulties and strategies to overcome these difficulties, leading them to perform actions in search of their linguistic and professional development.

KEYWORDS: language advising; autonomy; public schools.

\footnotetext{
${ }^{1}$ Este artigo é resultado de minha dissertação de mestrado.
} 


\section{Introdução}

Há no ensino de Língua Estrangeira (LE) a crença de que só se aprende inglês em curso livre. Dentre as razões que justificam a formação dessa crença encontram-se as péssimas condições da escola pública brasileira e a má formação do professor de inglês que sai da faculdade sem a preparação linguística e pedagógica necessária para o exercício de sua profissão (PAIVA, 1997; RATIER, 2011).

Dentro dessa perspectiva, essa pesquisa surgiu da necessidade de qualificação profissional dos professores de inglês que atuam nas escolas públicas. Meu objetivo era encontrar maneiras de melhorar a formação em serviço de professores de inglês que atuavam principalmente na rede pública de ensino no interior do Estado do Pará.

A metodologia de pesquisa adotada enquadra-se no paradigma qualitativo uma vez que se trata de uma pesquisa-ação. A pesquisa-ação proposta por este estudo parte do desenvolvimento da competência de aprender em direção ao desenvolvimento da competência linguageira, o que por sua vez, acredito que pode promover o desenvolvimento da competência pedagógica das professoras aconselhadas. Para tal, utilizei o AL como instrumento de fomento de autonomia. Nessa perspectiva, o AL apresenta-se neste trabalho, ao mesmo tempo, como objeto e instrumento de estudo (figura abaixo):

\section{Figura 1: Triângulo das competências do professor}

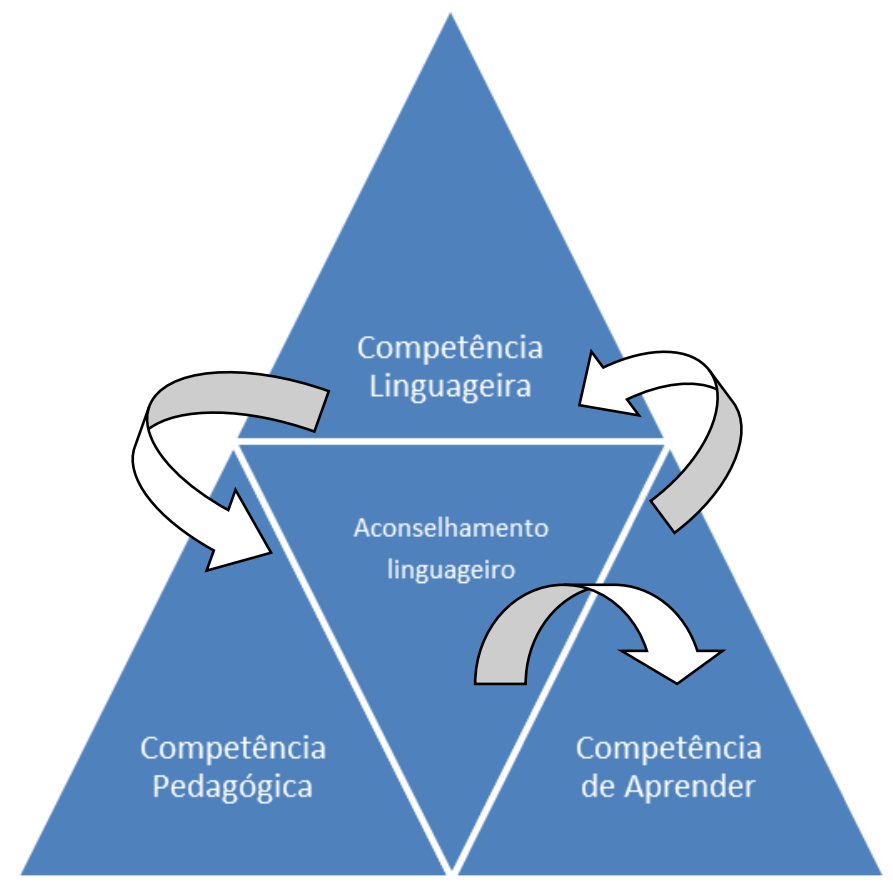

A hipótese de trabalho desta pesquisa partia, portanto, da ideia de que o período de aconselhamento agiria na competência de aprender do professor o que o tornaria mais autônomo na busca pela melhoria de sua competência linguageira, podendo com isso repercutir na promoção de um ensino melhor e mais comunicativo nas escolas onde atuavam esses sujeitos, uma vez que acredito que o aprimoramento da competência linguageira pode levar ao aprimoramento da competência pedagógica desses profissionais. 
O corpus deste estudo foi constituído das interações com duas professoras de inglês da Educação Básica de duas diferentes escolas públicas da cidade de Igarapé-Miri no Estado do Pará. As professoras em foco estavam envolvidas exclusivamente com o ensino de inglês na escola pública e ambas tinham formação superior na área de Letras - Inglês. Como forma de manter a identidade das professoras, adotei pseudônimos para identificá-las.

Semanalmente, conselheira e aconselhadas encontravam-se para as sessões de aconselhamento. Esses encontros eram presenciais e o horário e lugar de encontro quem definia era a aconselhada. Para efeito de organização das sessões de aconselhamento, utilizouse fichas de metas. As fichas de metas funcionavam da seguinte maneira: em uma sessão a aconselhada pontuava o que ela gostaria de melhorar e juntas, conselheira e aconselhada, construíam formas possíveis de aprimoramento; na sessão seguinte, fazia-se a avaliação do desempenho em relação ao que foi proposto na ficha de meta da sessão anterior. As sessões de aconselhamento costumavam durar de uma a duas horas e a conselheira procurava gravar áudios das sessões. Assim, para cada encontro com as aconselhadas, a conselheira redigia um relatório. Ao todo, foram cinco sessões de aconselhamento com cada uma das professoras, originando assim, dez (10) relatórios de sessões de aconselhamento. O conjunto destes constitui o instrumento de coleta de dados utilizado nessa pesquisa.

Este artigo está organizado de maneira que inicio fazendo um apanhado teórico dos principais construtos que embasam os estudos sobre aconselhamento linguageiro, tratando da definição do tema, da organização das sessões de aconselhamento e do perfil desejado do conselheiro linguageiro. Posterior a esse levantamento teórico, apresento a ressignificação de crenças como um dos resultados alcançados pela intervenção promovida pelo período de aconselhamento. Na sequência, algumas das ações desenvolvidas pelas professorasaconselhadas com o objetivo de superar as dificuldades são colocadas em destaque. Depois disso, apresento a avaliação das professoras sobre o aconselhamento linguageiro. Por fim, teço minhas considerações a respeito dos impactos do aconselhamento linguageiro na formação dessas professoras.

\section{Aconselhamento linguageiro}

Atualmente tem se discutido muito sobre o papel que o aluno deve exercer na aprendizagem. A corrente sócio interacionista postula que o conhecimento não é algo que se transfere de um ser para o outro, mas algo que é construído na interação entre sujeitos. Desta forma, para os teóricos pertencentes a essa linha do pensamento, o aluno deve exercer um papel ativo na construção de seus saberes e o professor deve deixar o centro do processo de ensino-aprendizagem para assumir o papel de mediador. É nesse contexto que surge um novo modo de suporte de aprendizagem de línguas que, partindo dos ideais construtivistas, promove o desenvolvimento do aluno tomando por base os seus interesses e as suas necessidades. Esse novo modo de suporte de aprendizagem de línguas ficou conhecido nos dias atuais como aconselhamento linguageiro (doravante AL).

\subsection{Definição}

O aconselhamento linguageiro é um campo de pesquisa que tem se tornado bastante popular no ensino de línguas devido às necessidades práticas, financeiras e pedagógicas de se aprender uma língua estrangeira em contextos que dificultam a participação em cursos regulares: distância dos centros de línguas, custo do curso, quantidade de alunos por turma etc. Ao mesmo tempo em que o AL possibilita uma aprendizagem mais autônoma, ele também pode exercer grande influência no processo de ensino-aprendizagem de línguas, 
apoiando as ações desenvolvidas pelo professor em sala de aula (GARDNER; MILLER, 1999; RILEY, 1997; VIEIRA, 2007).

Muitos estudiosos têm se ocupado com este tema e diversas definições já surgiram tentando esclarecer o que é o aconselhamento linguageiro. Todas essas definições, entretanto, seguem o mesmo caminho: direcionam o AL ao desenvolvimento da autonomia do aprendente.

Esch (1996) postula que o AL consiste em um sistema de intervenção que objetiva dar suporte à metodologia de aprendizagem de língua dos alunos utilizando-se para isso de conversas. Dessa forma, o AL como pensado por Esch (ibid) parte da interação verbal para ajudar o aluno a refletir sobre sua experiência de aprendizagem e a identificar inconsistências e orientar o seu próprio caminho.

Para Carson e Mynard (apud MYNARD, 2011), AL é um processo em que se oferece ajuda aos alunos com a intenção de direcioná-los para seus próprios caminhos, afim de torná-los melhores e mais autônomos na aprendizagem de língua.

Em um artigo intitulado "The what, why, and how of language advising", Reinders (2008) define aconselhamento linguageiro como sendo:

um tipo de suporte de língua em que os professores se encontram com os alunos de forma individual para oferecer conselhos e feedback e para ajudar os alunos a desenvolverem habilidades de aprendizagem auto-dirigida (REINDERS, 2008, p.1) $)^{2}$.

Para esse autor, o AL tem como principais objetivos fornecer orientações sobre o aprendizado de língua e encorajar o desenvolvimento da autonomia. Segundo Reinders (ibid), é nesse sentido que o AL se diferencia de tutoria e conferência, uma vez que o foco do AL não é diretamente a língua, como acontece nas duas atividades, mas sim as formas de se aprender a língua.

Ao falar sobre o AL oferecido de forma complementar ao ensino de sala de aula, Reinders (ibid) pontua que esse tem se tornado muito popular pois permite focalizar nas necessidades individuais do aprendiz, além de possibilitar uma maior ligação entre a sala de aula e a aprendizagem fora da sala de aula.

Para Mozzon-McPherson (1996), o AL é uma atividade de natureza colaborativa que envolve funções ativas, reativas e interativas. Segundo Mozzon-McPherson (2001), a identificação das necessidades e possíveis cursos de ação é co-construída por meio de negociação e interação ao invés de ensinada ou prescrita por um especialista.

Ao falar sobre os espaços de operação do aconselhamento, essa autora retoma o trabalho de Voller (1997) que, discutindo o papel do professor na aprendizagem autônoma, destaca quatro termos: facilitador, ajudante, conselheiro e consultor (VOLLER, 1997). Segundo Voller (ibid), os termos facilitador e ajudante estão mais relacionados ao ambiente de sala de aula, onde a função do professor é resumida como suporte técnico e psicossocial, enquanto que em atendimento individualizado o termo mais comumente utilizado é conselheiro.

\footnotetext{
${ }^{2}$ a type of language support where teachers meet with students on an individual basis to offer advice and feedback and to help students develop self-directed learning skills.
} 
Ainda segundo Mozzon-McPherson (2001), o espaço de operação do aconselhamento é na maioria dos casos o centro de auto-acesso. No entanto, Mynard (2011) salienta que o AL também pode ocorrer em sala de aula ou via linguagem escrita (através de diários, blogs etc.).

\subsection{Modelos de sessões de aconselhamento}

Ao descrever as sessões de aconselhamento, Reinders (2007) diz que correspondem a um ou mais encontros individuais, não necessariamente presenciais, conduzidos em qualquer língua que professor e aluno compartilhem, que se baseiam nas necessidades individuais de aprendizagem do aprendente e permitem uma maior ligação entre a sala de aula e a vida fora da sala de aula.

Geralmente, as sessões de aconselhamento consistem em um encontro entre um estudante e conselheiro para identificar as necessidades de aprendizagem, estabelecer prioridades, desenvolver um plano e discutir abordagens de aprendizagem (por exemplo, por meio de uma discussão de estratégias de aprendizagem). Nas sessões subsequentes, o conselheiro monitora o progresso e dá retorno, e geralmente continua acessível durante o período do programa para responder às perguntas dos alunos. Uma das principais características de sessões de aconselhamento é a tentativa de entregar para os alunos o controle do processo de aprendizagem, incentivando-os a refletir sobre o seu progresso, rever os seus próprios planos de aprendizagem e, talvez, por meio da auto-avaliação (REINDERS, 2007, p.79-80). ${ }^{3}$

Para Reinders (2008), as sessões de aconselhamento caracterizam-se também por: 1) serem negociadas: é muito importante sempre deixar o aluno em situação de escolha, oferecendo diferentes opções, o que quer dizer que o conselheiro linguageiro deve evitar oferecer conselhos diretos de execução de ações; 2) serem personalizadas: uma vez que as atenções devem estar voltadas para os desejos e necessidades dos alunos, as sessões de aconselhamento precisam ser organizadas de acordo com cada aluno; 3) serem flexíveis: o que significa que não se deve elaborar programas estruturados, pois as sessões variam de acordo com os objetivos e necessidades do aprendente no momento.

Ao diferenciar as sessões de aconselhamento das aulas de língua, Mynard (2011) destaca o caráter voluntário do aconselhamento. Segundo esse autor, as aulas de língua são compulsórias, os alunos são obrigados a assisti-las, enquanto que as sessões de aconselhamento devem ser voluntárias, pois só assim estaremos permitindo que o aluno assuma a responsabilidade por sua aprendizagem. Outra distinção apresentada por esse autor tem a ver com o que acontece nas sessões de aconselhamento. Para Mynard (2011), professores podem planejar e prever o que ocorrerá na aula, já conselheiros precisam sempre se adaptar e ter sensibilidade para perceber aquilo que os aprendentes trazem para as sessões de aconselhamento.

Mynard (ibid) resume o processo de aconselhamento por meio da seguinte figura:

\footnotetext{
${ }^{3}$ Generally, advisory sessions consist of a meeting between a student and advisor to identify learning needs, establish priorities, develop a plan and discuss approaches to learning (e.g. through a discussion of learning strategies). In subsequent sessions, the advisor monitors progress and gives feedback, and generally remains accessible for the duration of the programme to answer students' questions. One of the key characteristics of advisory sessions is the attempt to hand over to the students control of the learning process by encouraging them to reflect on their progress, revise their own learning plans, and perhaps through self-assessment (REINDERS, 2007, p.79-80).
} 


\section{Figura II: Processo de Aconselhamento}

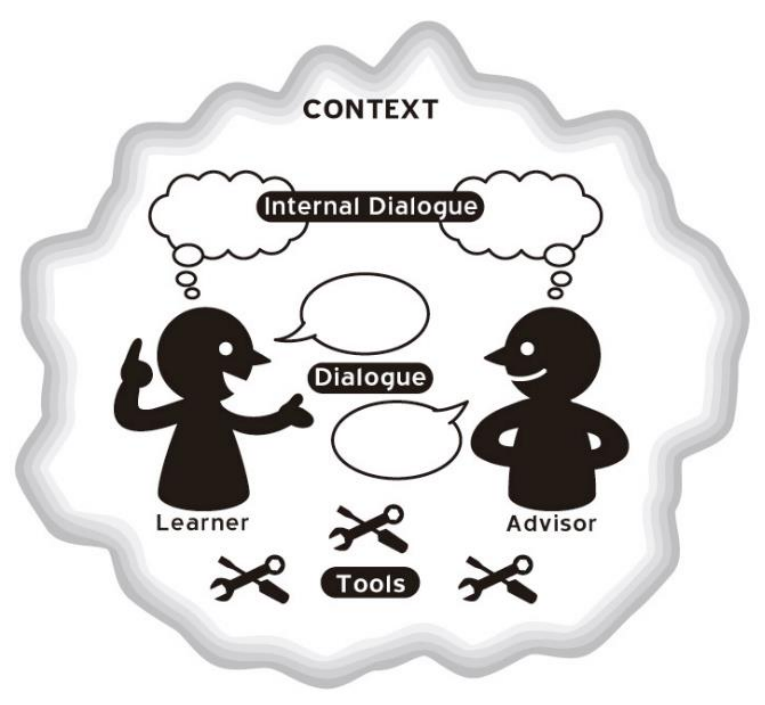

Diálogo, ferramentas e modelo de contexto (MYNARD, 2011, p.4)

Para esse autor, a combinação entre diálogo, ferramentas e fatores contextuais guia o processo de aconselhamento da seguinte forma: o aprendente fala enquanto o conselheiro escuta, questiona, orienta, encoraja etc.; o diálogo interno é muito importante (o aprendente pensa sobre como ele aprende, enquanto o conselheiro processa as informações e planeja como melhor orientar o aprendente a fazer conexões mais profundas; o conselheiro vale-se das mais variadas ferramentas para facilitar o processo (análise das necessidades, planos de aprendizagem, quadro de progresso, gráfico de motivação etc.); o contexto também é muito importante uma vez que ele está em constante mudança.

Reinders (2008) utiliza a figura abaixo para demonstrar que as sessões de aconselhamento correspondem a um período estendido, dão suporte ao auto-estudo e estão ligadas uma à outra permitindo com isso a continuidade do suporte.

Figura III: Organização das sessões de aconselhamento

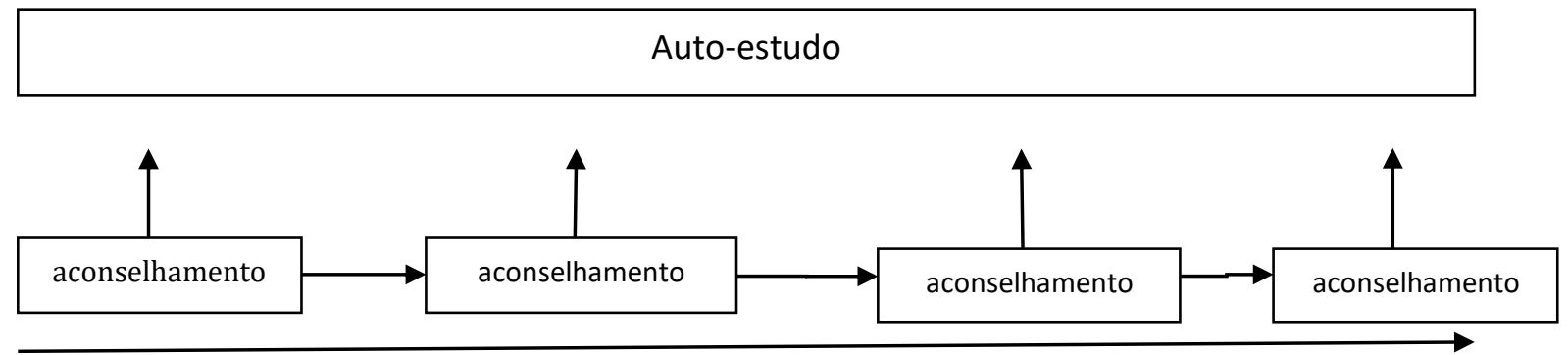

Tempo

(REINDERS, 2008)

$\mathrm{Na}$ proposta de Reinders (2008), as sessões de aconselhamento servem para dar suporte à aprendizagem fora de sala de aula, buscando com isso o desenvolvimento da autonomia do aprendente. Nessa proposta, encorajar o aprendente a conscientizar-se de sua aprendizagem é o principal objetivo. Isso ocorre gradativamente por meio de andaime 
cuidadoso: dá-se um pouco mais de orientação e suporte no estágio inicial e aos poucos vai se fazendo uma gradual transferência de responsabilidade e tomada de decisão para o aluno.

Em resumo, as sessões de aconselhamento são encontros individuais nas quais se observa as necessidades dos alunos e, a partir dessas necessidades, aluno e conselheiro constroem colaborativamente um plano de ação que poderá ser alterado cada vez que as necessidades mudarem.

\subsection{Perfil desejável do conselheiro linguageiro}

Segundo Mozzon-McPherson (2001), o conselheiro linguageiro é uma figura que gera empatia, ou seja, cria um ambiente em que o aprendente sente-se a vontade para falar de suas dificuldades e problemas de aprendizagem. Ainda segundo Mozzon-McPherson (ibid), o conselheiro linguageiro situa-se em uma área entre o professor e monitor do centro de autoacesso, o que faz com que acumule características de ambos os profissionais. Outra particularidade relevante do conselheiro linguageiro apresentada por esta autora é o fato de este não só dominar a língua estrangeira em estudo, como também possuir vasto conhecimento de estilos e estratégias de aprendizagem que são aspectos importantíssimos para a aprendizagem independente.

Para Riley (1997), o conselheiro é a pessoa que ajuda o aprendente a tomar as suas próprias decisões, tornando-o consciente de suas representações, crenças e atitudes. Para essa autora, aconselhamento é uma habilidade complexa que não pode ser adquirida da noite para o dia, pela simples mudança de sala ou uso de ferramentas diferentes. Riley (1997) acredita que assistir a uma sessão de um colega mais experiente, aprender uma nova língua em aprendizado auto-direcionado, compartilhar e discutir os temas pertinentes com outros conselheiros, fazer uma análise crítica das suas próprias sessões de aconselhamento e ouvir gravações de sessões são técnicas que podem ajudar a aprimorar a qualidade do aconselhamento.

Stickler (2001) estipula três habilidades básicas para um bom conselheiro linguageiro: ele deve ser uma espécie de guia, principalmente no que se refere às estratégias de aprendizagem de língua; precisa conhecer o ambiente de aprendizagem do aprendente para apresentar informações especializadas sobre recursos e materiais que o aprendente pode necessitar e dispor; e precisa ter ou desenvolver boas habilidades de aconselhamento para fazer das sessões de aconselhamento uma experiência enriquecedora e centralizado no aluno.

Mynard (2011), por sua vez, estabelece as seguintes funções de um conselheiro linguageiro:

1. Aumentar a consciência do processo de aprendizagem de língua;

2. Guiar o aluno;

3. Ajudar o aluno a identificar objetivos;

4. Sugerir materiais adequados, oferecendo opções de escolha, mais do que prescrever atividades;

5. Sugerir estratégias adequadas, oferecendo opções;

6. Motivar, dar suporte e encorajar o aprendizado autodirecionado;

7. Ajudar o aluno a se autoavaliar e refletir;

8. Ajudar o aluno a descobrir como ele aprende melhor;

9. Ouvir ativamente o aluno;

10. Ajudar o aluno a falar sobre seus problemas. 
Para Mozzon-McPherson (2008), o conselheiro linguageiro é responsável por:

oferecer orientação adequada e clara e apoio para que os alunos trabalhem autonomamente; ajudar a instituição a prover oportunidades de aprendizagem de línguas apropriadas; monitorar os padrões de aprendizagem dos usuários do serviço e prover retorno relevante e eficaz; monitorar a disponibilidade dos recursos disponíveis em relação as necessidades dos usuários; facilitar a habilidade dos aprendentes em tornarem-se mais proficientes por meio de um melhor entendimento do seu próprio processo de aprendizagem; ouvir as necessidades dos aprendentes e elicitar conversas sobre a língua e sobre a aprendizagem (MOZZON-MCPHERSON, 2008 apud MAGNO E SILVA, 2012, p. 216).

Sobre os conteúdos do aconselhamento, Mozzon-McPherson (2001), destaca que o conselheiro é especializado tanto na língua quanto em aprendizagem independente, e assume o papel de ponte na transição entre a sala de aula e o ambiente de aprendizagem independente. Por essa razão, os conteúdos de aconselhamento são ao mesmo tempo práticos e técnicos, tais como: rotular, catalogar e assegurar fácil acesso aos recursos; organizar visitas; conduzir sessões, oficinas sobre estratégias de aprendizagem; produzir folhetos e guias de estudo; usar análise de necessidades, contratos de aprendizagem, blogs, revistas para ajudar o aprendente a desenvolver sua consciência de aprendizagem de língua.

Para Kelly (1996), a grande diferença entre professor e conselheiro está no nível do discurso de cada um. Para diferenciar o nível de discurso entre professor e conselheiro, Kelly (ibid) distingue dois tipos de habilidades de aconselhamento as quais ela denominou macro e micro habilidades. Para Kelly (ibid), as macro habilidades são facilmente reconhecidas por bons professores, pois esses as usam frequentemente em suas salas de aula, enquanto que as micro habilidades estão mais relacionadas ao dia-a-dia do conselheiro linguageiro que as usa para tornar o ambiente de aconselhamento mais propício à reflexão e, consequentemente, à formação de aprendentes conscientes de suas responsabilidades em relação a aprendizagem. Abaixo apresento as macro e micro habilidades estabelecidas por Kelly (1996):

Quadro I: Macro e micro habilidades

\begin{tabular}{|c|c|}
\hline Macro habilidades & Micro habilidades \\
\hline $\begin{array}{l}\text { - Iniciar } \\
\text { - Estabelecer objetivos } \\
\text { - Guiar } \\
\text { - Modelar } \\
\text { - Dar suporte } \\
\text { - Dar retorno: } \\
\text { - Avaliar } \\
\text { - Vincular } \\
\text { - Concluir }\end{array}$ & $\begin{array}{ll}\text { - } & \text { Atender } \\
\text { - } & \text { Reafirmar } \\
\text { - } & \text { Parafrasear } \\
\text { - } & \text { Resumir } \\
\text { - } & \text { Questionar } \\
\text { - } & \text { Interpretar } \\
\text { - Evidenciar sentimento } \\
\text { - Criar empatia } \\
\text { - Confrontar }\end{array}$ \\
\hline
\end{tabular}

Quadro de habilidades proposto por Kelly (1996)

Assim, de acordo com Kelly (1996), os professores em suas aulas geralmente introduzem novos direcionamentos e opiniões com a intenção de colocar o aprendente em foco e reduzir incertezas, ajudam o aprendente a formular objetivos específicos que possam ser metas administráveis oferecem conselhos e informações, direção e ideias para ajudar o aluno a desenvolver estratégias alternativas, demonstram comportamentos desejáveis, proporcionam incentivo e reforço, expressam uma reação construtiva ao esforço do 
aprendente, verificam o progresso do aprendente, estabelecem ligação entre os objetivos do aprendente e tarefas com questões mais amplas, e ainda ajudam o aprendente a estabelecer limites e definir conquistas, valendo-se assim das macro habilidades, habilidades estas que compartilham com os conselheiros linguageiros.

Já o conselheiro linguageiro, visando o atendimento individualizado, precisa se valer, além das macro habilidades, das micro habilidades mencionadas acima. Assim o discurso do conselheiro deve procurar sempre mostrar respeito e interesse pelo que o aprendente está dizendo, repetir com suas próprias palavras aquilo que o aprendente disse para confirmar sua compreensão, simplificar o que o aluno disse focalizando na essência da mensagem para esclarecê-la e resolver qualquer confusão na compreensão, reunir os principais elementos da mensagem para criar foco e direção, usar perguntas para encorajar a auto exploração, oferecer explicações para as experiências do aprendente, colocar em evidencia o conteúdo emocional apresentado pelo aluno, identificar-se com as experiências e percepções do aprendente de forma a criar um vínculo de entendimento compartilhado, assim também como tentar demonstrar discrepâncias e contradições na comunicação do aluno.

Em resumo, as definições acima deixam clara a íntima ligação existente entre o aconselhamento linguageiro e a autonomia, posto que as práticas de aconselhamento se estendem muito além das sessões de aconselhamento. No entanto, segundo Magno e Silva (2012, p. 218), o objetivo do aconselhamento só será alcançado se se criar "uma atmosfera que maximize a autonomia do aprendente e que minimize as intervenções em tom professoral apontando soluções para os problemas do aprendente".

\subsection{O AL e a ressignificação de crenças}

As crenças mais significativas percebidas durante esta pesquisa foram: crença de que só se aprende inglês em curso livre, crença de que o professor precisa saber tudo; e crença de que professores estudam somente para dar aula. As sessões de aconselhamento partiram da confrontação dessas crenças, pois acredito que algumas delas estavam impedindo os sujeitos de assumir o controle da sua aprendizagem, deixando a apropriação de algumas habilidades e/ou conteúdos ora para quando precisassem desse conhecimento para lecionar, ora para quando tivessem tempo para estudar em um curso livre.

A minha primeira preocupação enquanto conselheira foi fazer com que as professoras se conscientizassem da existência dessas crenças, para tanto adotei a técnica de questionamento apresentada por Kelly (1996). Perguntei a professora Ana, por exemplo, o porquê de ela esperar para quando ela poder voltar para um curso livre para começar a buscar sua tão sonhada fluência em inglês. Perguntei ainda a ela se realmente acredita que só num curso livre ela conseguiria desenvolver o seu inglês. Relatei a essa professora histórias de sucesso de pessoas que nunca frequentaram cursos livres e têm uma excelente fluência em inglês, histórias essas que li em outras narrativas de aprendizagem. Após ouvir as histórias, a professora Ana ficou bastante empolgada e ansiosa para começar a ação, demonstrando com isso que ela percebeu a partir das histórias dos outros que a sua fluência em inglês dependia muito mais de si mesma do que de algum curso de que pudesse participar.

Com Helena adotei estratégia similar. No entanto, essa professora informou já ter passado por diversos cursos livres na busca pela sua proficiência linguística. Assim perguntei a ela porque ela havia trocado tantas vezes de curso livre. Helena informou que quando não gostava da metodologia do curso e achava que não estava evoluindo procurava outro curso. Nesse momento senti a necessidade de questionar sobre como eram as aulas dos cursos livres que ela participou e ela me relatou que na maioria deles, o foco era dado à gramática e pouco ou nada se via de comunicação oral. Relatei a professora Helena minha passagem por um 
curso livre de Belém, onde boa parte das atividades orais eram apenas repetição das conversas do livro e contei a ela que já estando no penúltimo nível decidi abandonar o curso pois percebi que aquele curso livre com seu método de repetição estava me desmotivando a aprender. Fiz isto com a intenção de criar empatia e fazer com que a professora percebesse que esse tipo de situação não aconteceu só com ela. Aqui foi interessante que a pergunta seguinte partiu da professora que me indagou sobre o que eu passei a fazer para melhor o meu inglês. Nesse momento, falei a ela sobre diversas atividades que passei a realizar em casa, como ouvir músicas, assistir a filmes, criar flashcards de vocabulário novo e cartões de tópicos para conversação, coisas essas que não fazia enquanto estava no curso livre. A percepção da professora Helena sobre o quanto ela estava insistindo com os cursos livres e o pouco que ela estava fazendo por si mesma enquanto aprendente de inglês foi quase que imediata. Esta professora finalizou a sessão dizendo o seguinte:

(1) Se eu tivesse que aprender em curso livre já teria aprendido, pois eu já passei por um montão deles e até agora ainda não saí do inglês básico (Helena, sessão de aconselhamento).

É interessante lembrar que a crença de que só se aprende inglês em curso livre está diretamente ligada a crença de que não se aprende inglês em escolas públicas. É nesse sentido que vi a imediata necessidade de ressignificação dessa crença, pois, se como professora de inglês de escolas públicas, eu acredito que o lugar de aprendizagem de línguas no Brasil é o curso livre de idiomas, eu estou admitindo que meu trabalho é ineficiente e pouco significativo, pois comigo o aluno nunca vai aprender a língua de fato, o que por outro lado afeta a minha motivação em ensinar e a minha autoestima profissional.

Conscientizar-se da necessidade de assumir o controle sobre a sua aprendizagem permite que o sujeito entenda que para aprender um idioma é necessário muito mais do que frequentar aulas, é necessário se conhecer melhor e conhecer suas necessidades. Essa conscientização também faz com que este sujeito enxergue o curso livre de idiomas apenas como uma das possibilidades de melhorar e praticar o inglês entre uma variedade enorme de possibilidades disponíveis atualmente.

Outra crença que precisou ser confrontada durante as sessões de aconselhamento foi a de que só se estuda para dar aula. As professoras-aconselhadas desta pesquisa relataram estarem acostumadas a estudar um determinado tópico ou verificar a pronúncia de determinada palavra somente quando precisavam dar aula sobre esse tópico e/ou palavra. Fazer com que as professoras se percebessem também como aprendente da língua foi uma tarefa bastante complicada, pois tudo a que elas se referiam no início do aconselhamento relacionava-se as suas formas de ensinar e não às suas formas de aprender. Com isso, as professoras não tomavam atitudes para aumentar suas competências linguageiras. Suas ações relacionavam-se apenas a conteúdos de ensino. Para confrontar essa crença, foi necessário pedir para que estas professoras esquecessem a princípio as suas salas de aulas e procurassem enxergar os conteúdos e recursos disponíveis visando à sua aprendizagem e não mais a de seus alunos. Confrontar esta crença possibilitou a criação de conteúdos de aprendizagem voltados para as necessidades de aprendizagem de cada uma das professoras aconselhadas desta pesquisa, o que, por sua vez, pouco ou nada estava relacionado aos conteúdos que essas professoras estavam ensinando na escola pública durante o período de aconselhamento.

Colocar as professoras de volta na posição de aprendente também possibilitou que estas entendessem que seu papel em sala de aula não era mais o de detentora do conhecimento, o que refletiu por sua vez na confrontação da crença de que o professor precisa saber tudo, posto que não carregavam mais consigo a responsabilidade de ser aquele que sabe 
tudo sobre a língua em estudo. Para exemplificar a mudança de atitude desses professores no que se refere à ressignificação desta crença, apresento o trecho abaixo:

(2) Eu posso dizer para eles que eu não sei, mas que vou pesquisar e na próxima aula trago a resposta ou eu posso fazer melhor, pedir para que eles pesquisem sobre isso e que eu vou pesquisar também e que na próxima aula a gente ver como fica (Helena, sessão de aconselhamento).

Ao se ver como aprendente da língua, a professora Helena passou a conscientizar-se que não precisava saber tudo sobre a mesma, posto que ela assim como seus alunos estava em processo de construção de conhecimento. Por outro lado, o fato de a professora também ser uma aprendente em sala, não a desabilita a ensinar o idioma, uma vez que os níveis de conhecimento sobre o objeto de estudo são distintos e a professora continua podendo exercer o papel de sujeito mais capaz (nos termos vygotskyanos), agindo na ZDP do aluno.

\subsection{O AL e os primeiros passos visando a superação das dificuldades}

As sessões de aconselhamento partiam daquilo que as professoras já sabiam a respeito da língua em direção a construção ou ao aprimoramento de novas habilidades. Para tanto, a conselheira pedia as aconselhadas que refletissem sobre o que elas já sabiam fazer com a língua, o que elas gostariam de aprender a fazer a partir de agora e o que elas acreditavam que precisavam fazer para alcançar seus objetivos. Assim, as aconselhadas construíram seus objetivos em relação ao inglês e colaborativamente conselheira e aconselhadas discutiram formas de alcançar esses objetivos. A execução dessas ações evidenciou uma mudança de atitude por parte das aconselhadas que se mostraram preocupadas em iniciar um processo de tomada de controle sobre a sua aprendizagem visando o seu aprimoramento pessoal e profissional.

A professora Ana decidiu que iria tentar estabelecer diálogos simples com pessoas que soubessem inglês. Não encontrando ninguém em seu convívio regular que dominasse essa língua para dialogar com ela, essa professora também teve a iniciativa de inscrever-se em um curso básico de inglês online para praticar diálogos. No entanto, não teve como fazer o curso online porque sua internet não funcionava bem para esse tipo de curso.

Como Ana entendia que tinha um grande problema de audição em inglês, essa professora procurou ouvir música para melhorar a audição. Foi ao tentar compreender essas músicas que Ana percebeu que a sua maior dificuldade de língua não era nem ouvir, nem falar, como ela pensava. Depois de não conseguir compreender essas músicas, mesmo acompanhada das letras, e questionada sobre o porquê de não ter compreendido, a professora Ana percebeu que a razão pela qual não alcançava a compreensão era o fato de ela não possuir um vasto acervo vocabular. Aqui se verifica a ação do AL na percepção das reais dificuldades. O AL ajudou a professora Ana a perceber que sua compreensão oral dependia sobremaneira de seu vocabulário. A partir daí Ana descobriu que seu vocabulário era a sua maior dificuldade e começou a estabelecer estratégias para aprimorá-lo.

Para expandir seu vocabulário, por sua vez, Ana se propôs fazer flashcards, tarefa essa que alegou na semana seguinte não ter encontrado tempo para realizar. No entanto, essa professora pesquisou na internet novas formas de fixar vocabulário, utilizou um dicionário eletrônico para saber o significado das palavras que não conhecia nas músicas e praticar a pronúncia. Essa atividade fez com que Ana percebesse que é altamente visual, o que a levou a organizar o seu próprio dicionário anotando em um caderno todas as novas palavras que encontrava nas músicas que ouvia. 
Outra ação que Ana conseguiu realizar foi, após ouvir várias vezes as músicas, cantálas e gravar-se cantando em seu celular. Ana também se propôs ler uma história em inglês, resumi-la e recontá-la também em inglês. Ela foi capaz de realizar essa tarefa, no entanto para relatar a história, Ana precisou escrever em um papel e tê-lo em mãos para recontar.

É importante ressaltar que apesar de não ter alcançado todas as metas estabelecidas, essa professora revelou estar iniciando um processo de autonomização. De fato, ela não fez algumas coisas que ela se comprometeu a fazer, mas, por outro lado, ela fez outras coisas que não tinham sido mencionadas, o que caracteriza um certo nível de autonomia.

É importante ressaltar também que o aconselhamento ajudou a professora Ana a refletir sobre as estratégias que estava utilizando. No decorrer das sessões de aconselhamento, essa professora percebeu que a sua estratégia de verificar no dicionário digital a pronúncia de determinada palavra em nada a estava ajudando a aprimorar sua habilidade de produção oral.

Helena por sua vez se propôs em um primeiro momento selecionar uma lista de verbos irregulares para estudar, criar flashcards associando a imagem às formas presente e passado dos verbos, pensar em frases com esses verbos, utilizando-as no presente e no passado, ouvir a pronúncia dos verbos no dicionário digital e repetir quantas vezes possível para alcançar uma pronúncia mais próxima.

No encontro seguinte, Helena alegou que não encontrou tempo, pois precisou acompanhar a mãe que estava doente. Nessa sessão, conselheira e aconselhada selecionaram juntas a lista de verbos irregulares. A partir desta lista a aconselhada criou frases com os verbos irregulares que ela já conhecia em um trabalho conjunto com a conselheira, no qual a conselheira dizia um verbo e um tempo verbal e a aconselhada criava oralmente frases com o verbo. A aconselhada ficou de fazer o mesmo com os demais verbos da lista.

Como percebi que essa professora tinha muita dificuldade em organizar o seu tempo para realizar as ações necessárias ao desenvolvimento do seu inglês, imaginei uma estratégia que pudesse demonstrar a ela que mesmo com a sua grande carga-horária havia alguma forma de arranjar tempo em seu dia atribulado para praticar o inglês. Foi aí que propus a ela que fizesse do momento de ir para cama o momento de praticar o inglês ouvindo e ou lendo alguma coisa em inglês. Para exemplificar o que estava dizendo, mostrei a ela alguns livrosáudio que comprei na época do meu curso de graduação e falei a ela que com esses livros conseguia praticar as quatro habilidades, pois toda a noite antes de dormir realizava algum tipo de atividade com algum daqueles livros, que geralmente seguia a seguinte ordem: primeiro eu escutava a história várias vezes, a partir daí eu criava a minha interpretação sobre o que tratava o livro; depois eu ia ao livro de fato para confirmar se as hipóteses que havia estabelecido com a audição eram verdadeiras. Enquanto lia já ia marcando o vocabulário que não conhecia e checando no dicionário. Feito isso ia para o papel e resumia a história para no final encontrar alguém na faculdade que me escutasse contar a história. Helena achou a atividade interessante e resolveu experimentar. Na primeira noite, ela ouviu a história e relatou que teve um pouco de dificuldade em compreender. Entretanto, Helena conseguiu realizar até o final todas as etapas dessa atividade que inclusive ela disse ter gostado muito.

\subsection{Efeitos do aconselhamento: percepções das professoras}

Durante as sessões de aconselhamento, Ana mostrou-se muito entusiasmada com o desenvolvimento de seu inglês, pois, segundo ela, sentia que estava avançando e acreditava que esse avanço resultava das reflexões feitas durante as sessões de aconselhamento. Desta forma, a professora Ana avaliou a intervenção promovida pelo aconselhamento como 
positiva. Na fala seguinte, essa professora chama a atenção para a importância das sessões de aconselhamento para a sua tomada de atitude:

(3) Rejane, porque tu não fizesses o teu mestrado antes? Se tu tivesses feito o teu mestrado antes eu já estava bem adiantada no inglês agora (Ana, sessão de aconselhamento).

A professora Helena também revelou estar muito entusiasmada, pois sentia agora que era capaz de fazer uma variedade de coisas diferentes. Helena também relata que graças a incentivos que recebeu nas sessões criou coragem e ministrou a sua primeira aula com música. Ao relatar isso ela pareceu muito motivada, pois tinha sentido que pela primeira vez a aula havia agradado os alunos.

(4) Hoje eu tomei coragem e levei uma música para a aula. Os alunos adoraram. Claro que eu não li a música. Eu coloquei ela para tocar e pedi que eles preenchessem o que faltava. Foi uma atividade simples e eu morria de medo de não dar conta, de não entender o que estava na música, mas deu tudo certo. Estou muito feliz (Ana, sessão de aconselhamento).

Helena também relatou que durante um curso de formação para professores encontrou com um cantor na porta do prédio onde o curso acontecia. Esse cantor era nativo e esposo de uma das professoras do curso. Ele imediatamente tentou manter comunicação com ela, mas Helena fugiu da conversa pois achava que ainda não era boa o suficiente para estabelecer diálogos. O cantor insistiu. Foi quando ela disse ter ouvido a minha voz falando com ela: "aproveite as oportunidades, aproveite as oportunidades de usar o idioma". Frase essa que havia dito a ela na sessão de aconselhamento anterior quando ela contou sobre sua dificuldade de falar. Naquele momento, Helena não conseguiu mais do que cumprimentar o cantor tendo em vista o seu pouco domínio da língua. No entanto, esse episódio deixa evidenciado o processo de internalização da fala do conselheiro na construção da autonomia do aconselhado, que ao reconstruir e internalizar o discurso do aconselhamento percebe as oportunidades de praticar a língua que surgem em seu dia a dia (VYGOTSKY, 1984).

\section{CONSIDERAÇÕES FINAIS}

Como apresentado anteriormente, esta pesquisa-ação se propunha encontrar maneiras de melhorar a formação em serviço de professores de inglês que atuavam na rede pública de ensino no interior do Estado do Pará. Para tanto, busquei compreender melhor o contexto onde atuavam os professores sujeitos desta pesquisa e procurei identificar quais eram suas principais dificuldades no exercício da profissão para, a partir daí apoiá-los por meio do aconselhamento linguageiro a aprimorar as suas competências tanto linguageira quanto pedagógica.

Como conclusão dessa pesquisa posso dizer que o aconselhamento linguageiro permitiu a ressignificação de crenças que, por sua vez, fez com que as professorasaconselhadas enxergassem o seu real papel na aprendizagem e buscassem alternativas para aprimorar o seu inglês.

O AL também conduziu as professoras-aconselhadas a avaliar suas estratégias, levando-as a perceber que as estratégias que estavam utilizando para desenvolver determinada habilidade não eram apropriadas para alcançar o objetivo proposto. Assim também como o AL, por meio de questionamentos, permitiu que as dificuldades pudessem ser redefinidas e especificadas. 
Ressalto também aqui o papel motivador que o AL exerceu no desenvolvimento dessas profissionais. À medida que as sessões de aconselhamento se sucediam, as aconselhadas sentiam que estavam avançando e quanto mais percebiam seus avanços mais realizavam ações de aprendizagem.

Um dos principais problemas enfrentados durante o período de aconselhamento, entretanto, relaciona-se ao espaço de aconselhamento. Como as sessões de aconselhamento aconteciam na casa das aconselhadas, estávamos sempre sujeitos a interrupções pela família das aconselhadas. Outro problema que tivemos de enfrentar com bastante frequência foi o pouco tempo livre que as professoras tinham disponível tanto para se encontrar com a conselheira quanto para realizar as tarefas que haviam determinado para a semana: a maioria dos professores de inglês da rede pública do interior possui dois vínculos empregatícios, uma vez que a carência desses profissionais ainda é muito grande. Uma possível solução para esse problema é buscar parceria com as Secretarias de Educação tanto para que estas disponibilizem um tempo dentro da carga-horária desses profissionais para o aconselhamento, quanto para que estas forneçam um espaço mais apropriado ao aconselhamento.

É importante ressaltar que o período de aconselhamento compreendeu apenas cinco sessões, o que considerando a dificuldade de tempo equivaleu a basicamente dois meses. Os poucos avanços relatados na seção anterior foram minhas percepções dentro desse período. Assim, para uma pesquisa posterior, crio a hipótese de que um período de aconselhamento mais longo (pelo menos um ano) em parceria com uma Secretaria de Educação que viabilizasse espaço e tempo para o aconselhamento seria uma excelente formação continuada para quem não tem como frequentar cursos de formação tradicionais. Estou certa de que, acompanhadas por um longo período, as professoras elevariam seu nível de autonomia o que poderia ser constatado via observação de suas aulas que certamente estariam muito mais motivadoras e comunicativas.

\section{Referências}

ESCH, E. Promoting learner autonomy: criteria for the selection of appropriate methods. In: PEMBERTON, R. et al. Taking control: autonomy in language learning. Hong Kong University Press, p. 35-48, 1996.

GARDNER, D.; MILLER, L. Counseling. In: to practice. Cambridge: Cambridge, 1999. Establishing self-access. From theory

KELLY, R. Language counseling for learner automony. In: PEMBERTON, R. et al. (eds.). Tanking control: Autonomy in language learning. Hong Kong University Press, 1996.

MAGNO E SILVA, W. Autonomia, motivação e aconselhamento linguageiro na sala de aula de línguas. In: MENDES, E.; CUNHA, J. C. Práticas em sala de aula de línguas: diálogos necessários entre teoria(s) e ações situadas. Campinas, São Paulo: Pontes Editores, 2012.

Aconselhamento Linguageiro: Visando à motivação e à Autonomia na Aprendizagem de Línguas Estrangeiras. Belém: Faculdade de Letras Estrangeiras Modernas, Instituto de Letras e Comunicação, UFPA, 20 p, 2013 (Relatório final de pesquisa).

MOZZON-MCPHERSON, M. The language adviser: a new type of teacher. In LITTLE D.; VOSS B. (eds.). Language centres: planning for the new millennium. Plymouth: CercleS. p. 97-109, 1996. 
MOZZON-McPHERSON, M.; VISMANS, R. (Eds). Beyond language teaching towards language advising. London: CILT, 2001.

MYNARD, J. The role of the learning advisor in promoting autonomy.2011. Disponível em: http://ailarenla.org/lall. Acesso em 21 de novembro de 2012.

PAIVA, V. L. M.O. A identidade do professor de inglês. Revista APLIEMGE: ensino e pesquisa. Uberlândia: APLIEMGE/FAPEMIG, n.1, p. 9-17, 1997.

RATIER, R. Ir além do ensino para inglês. Revista Nova Escola. V. XXVI, no . 243, junho/julho, p. 28-30, 2011.

REINDERS, H. University language advising: is it useful? In: Reflections in English Language Teaching, - nus.edu. 2007.

REINDERS, H. The what, why, and how of language advising. In: MexTESOL, v. 32, $\mathrm{n}^{\circ} .2$, 2008 .

RILEY, P. The guru and the conjurer: Aspects of counseling for self-access. In: BENSON, P.; VOLLER, P. (Eds.). Autonomy and Independency in Language Learning. London: Longman, 1997.

STICKLER, U. Using counseling skills for advising. In: MOZZON-McPHERSON, M.; VISMANS, R. (Eds) Beyond language teaching towards language advising. London: CILT, 2001.

VIERA, F. Teacher development through Inquiry: Getting Started. In: BARFIELD, A.; BROWN, S.H. (Eds.). Reconstructing Autonomy in Language Education: Inquiry and Innovation. London: Palgrave, 2007.

VOLLER, P. Does the teacher have a role in autonomous language learning? In: BENSON, P.; VOLLER, P. Autonomy e independence in language learning. New York: Longman, 1997.

VYGOTSKY, L. S. A Formação Social da Mente. São Paulo, Martins Fontes, 132 p, 1984. 